\title{
Emission Evaluation of Different Types of Liquefied Wood
}

\author{
Tine Seljak ${ }^{1,2,{ }^{*}}$ - Matjaž Kunaver1 - Tomaž Katrašnik² \\ ${ }^{1}$ Centre of Excellence Polimat, Slovenia \\ 2 University of Ljubljana Faculty of Mechanical Engineering, Slovenia
}

After initial studies, further research work on the combustion properties of second generation biofuels, obtained through solvolysis in polyhydroxy alcohols is oriented towards different types of liquefied wood that exhibit several favorable properties. In this study, different types were obtained by altering the reactant ratios of the fuels. These were focused on increased wood content and elevated pH value that would increase the techno-economic attractiveness of the fuel.

Three different types of fuels were tested in a laboratory scale gas turbine, and evaluated through $\mathrm{CO}$, THC and $\mathrm{NO}_{\mathrm{x}}$ emissions measurements, while varying multiple operating parameters. To achieve sufficient atomization quality, the high viscosity of the fuels was reduced by preheating to $100^{\circ} \mathrm{C}$. To speed up the droplet evaporation process and additionally to resemble conditions present in commercially available systems, high temperatures of primary air were employed by the use of exhaust gas heat regenerator. CO and THC emissions were found to be highly dependent on wood content and turbine inlet temperature, whereas with partial neutralization of the fuel this dependency was less pronounced and only $\mathrm{NO}_{x}$ concentrations were influenced by altered elemental composition of the fuel.

Results indicate it is possible to maintain successful combustion in microturbines even with fuels that exhibit higher pH value and reduced reactivity and with fuels containing higher amounts of lignocellulosic biomass.

Keywords: biomass, fuel, gas turbine, emissions, waste to energy, solvolysis

\section{O INTRODUCTION}

Increasing interest in biofuels and fuels produced from waste materials is mainly driven by the goal to replace fossil fuels in specific applications. Presently, ethanol and biodiesel have the largest share as they closely resemble physical and chemical properties of the petroleum distillates and thus require only minor modifications of the existing spark ignition (SI) and compression ignition (CI) engine technology, whereas some engines are already suitable for direct use of these fuels as shown in [1]. Production of biodiesel is based mainly on the rapeseed and soybean feedstock, and ethanol is mainly obtained through fermentation of sugar cane and corn starch and thus both compete with food feedstock [2].

Therefore primary materials for the second generation biofuels are frequently selected from a large pool of lignocellulosic feedstock. Although lignocellulosic materials can be used in external combustion systems for small CHP applications [3], different processes are available for depolymerization of relatively complex molecules of lignin, cellulose and hemicelluloses that constitute lignocellulosic materials. Through these processes lignocellulosic materials are converted to gaseous or liquid fuels and are applicable directly in internal combustion engines. Besides production of cellulosic ethanol which features low efficiency as mainly cellulose is converted to the fuel [4], several thermochemical procedures can also be utilized to decompose lignin molecules. Although thermochemical procedures generally yield heavier biofuels, they are still promising as some of the products can be directly used in low and medium speed diesel engines and gas turbines [5]. Currently the main research focus is on pyrolysis oils (liquid fraction of pyrolysis process) which are extensively reviewed in [6], and possibilities for their exploitation are presented in [5]. Almost any polymer material can be used for production of pyrolysis oils, although tires and biomass are the most widely used feedstocks [7]. The physical and chemical properties of pyrolysis oils are dependent on the feedstock composition and the type of the pyrolysis process. Generally, lignocellulosic waste of different origins yields oils with high viscosity ( 15 to $35 \mathrm{cSt}$ at $40{ }^{\circ} \mathrm{C}$ ) and low calorific value $(\sim 20 \mathrm{MJ} / \mathrm{kg})$ [5]. Severe reaction conditions required for pyrolysis with temperatures exceeding $500{ }^{\circ} \mathrm{C}$ [6] usually dictate the choice of expensive materials and advanced process equipment.

Depolymerization of biomass constituents can also be realized through liquefaction in different media, e.g. water and different alcohols. Required process temperatures and pressures with water are in the vicinity of critical point $\left(280\right.$ to $370{ }^{\circ} \mathrm{C}$ and 100 to $250 \mathrm{bar}$ ) [8]. The advantage of direct liquefaction becomes apparent with the use of the phenol or multifunctional alcohols, since process conditions are significantly less severe in this case. This process could therefore be viable on small and medium scale where the initial investment cost is often a key factor for profitability.

When converting biomass, both processes, i.e. pyrolysis and liquefaction in multifunctional alcohols, 
yield fuels with low $\mathrm{pH}$ value and high viscosity. In pyrolysis oils, low $\mathrm{pH}$ value is a consequence of high acid content; up to $10 \%$ hydroxyacetaldehyde, roughly $5 \%$ acetic acid and around $3 \%$ formic acid. The consequent $\mathrm{pH}$ value is usually between 2 and 3 . In products of direct liquefaction in multifunctional alcohols, high acidity arises no only from acidic decomposition products as in pyrolysis oils but also from the use of acids as catalysts $\left(\mathrm{H}_{2} \mathrm{SO}_{4}\right.$, $\mathrm{Ts} \mathrm{OH})$. Besides acidity, these fuels exhibit relatively high viscosity which arises from relatively large molecules obtained through depolymerization of lignin and cellulose. For successful use in combustion applications, preheating is usually required to reduce the viscosity which is required to achieve sufficient atomization quality. Conditions during preheating combine high temperature and low $\mathrm{pH}$ value; this presents highly corrosive environment requiring careful selection of materials used in fuel and injection system to avoid failures due to corrosion of components.

Liquefied wood (LW) was suggested as a fuel in [9], although the presented process featured an additional upgrading step with catalytic hydrotreatement to reduce the viscosity and elevate the heating value. Although, studies in [9] and [10] indicated the use of hydrotreated LW as a fuel, no data on combustion of such an upgraded type of LW was found during extensive literature survey. In contrast, authors of this paper presented primary results on combustion of non-upgraded LW in [11], which indicates that catalytic hydrotreatement of the LW as proposed in [9] and [10] is not always necessary. Instead, viscosity can be lowered by altering reactant ratios as presented in [12]. In addition, this measure can be succeeded by preheating of the fuel and thus viscosity can be sufficiently reduced to reach acceptable $\mathrm{CO}$ and THC emissions.

Following a successful demonstration of combustion capabilities of the LW in [11] this study focuses on analyses of combustion and emission formation phenomena of different types of LW. This research is motivated by the fact that efficient exploration of different LW types extends the knowledge base on the influencing and governing mechanisms of combustion and emission formation of different fuel types and significantly contributes to the successful application of this innovative biofuel.

Low price and availability of biomass is the main driver for increasing biomass content to boost the economic attractiveness of one LW type. Additionally, the LW type with more neutral $\mathrm{pH}$ value will be tested on its combustion characteristics. The main motive for this lies in reduced reactivity of the partially neutralized LW exhibiting increased storage stability and stability at high temperatures. This is the consequence of acid catalyst neutralization which then shifts the temperature threshold of liquefaction reactions higher and prevents solid residue formation during preheating phase [13]. Preliminary indications exist that elevated $\mathrm{pH}$ value could also reduce the corrosivity of such fuel and in this way reduce the process equipment and fuel system material costs. The influence of altered chemical composition and product reactivity on combustion performance and exhaust emissions will be evaluated through emission measurements. Experiments are performed in an experimental gas turbine, designed exclusively for combustion analyses of heavy fuels at different operating regimes.

\section{MATERIALS}

In the results section, baseline measurements were performed by firing diesel fuel, compliant with the EN 590 standard. Fuel production processes of the three types of the LW are described below.

\subsection{Fuel Processing}

LW was produced through aforementioned solvolysis of spruce wood in polyhydroxy alcohols. Although solvolysis in various media is a well-known process, its subtype, glycolysis, is still a relatively unknown procedure for fuel production. Liquefaction of isolated cellulose and lignin in multifunctional alcohols was already studied in [14] to [16], whereas studies investigating liquefaction of naturally combined lignin and cellulose in woody biomass were conducted in [9], [10] and [17]. In all of the above cases, lignocellulosic material was added to the glycols mixture and heated for sufficient time in temperature interval between 120 to $250{ }^{\circ} \mathrm{C}$. The reaction rates were increased substantially by the use of acid catalysts. Details of the liquefaction process are provided in Table 1. Efficiency of conversion of initial material (wood) to liquid products depends mainly on:

Acidity: A high concentration of acid catalyst results in increased rate of recondensation reactions after the highest degree of depolymerization is already achieved. If the reaction conditions are maintained, products are prone to formation of the solid residue which influences both the efficiency of conversion and process complexity due to filtering demands. Formation of residue occurs as a consequence of recombination of liquefaction products [13]. On 
the other hand, too low acid concentration needs to be compensated by higher process temperature and prolonged liquefaction time [17]. The amount of acid catalyst should therefore be carefully determined as it plays a crucial influence on liquefaction efficiency.

Table 1. Reaction parameters for fuel production

\begin{tabular}{ll}
\hline Process & Solvolysis in acidified polyhydroxy alcohols \\
\hline Temperature & $180{ }^{\circ} \mathrm{C}$ \\
\hline Pressure & Atmospheric \\
\hline Catalyst & TsOH (tosylic acid $\mathrm{CH}_{3} \mathrm{C}_{6} \mathrm{H}_{4} \mathrm{SO}_{3} \mathrm{H}$ ) \\
\hline Residence time & 180 min, mixing \\
\hline Feedstock & Spruce wood flour \\
\hline Solvent & Glycerol, di-ethylene glycol \\
\hline
\end{tabular}

Biomass to solvent ratio: The efficiency of conversion significantly decreases if the biomass to solvent ratio exceeds 1 . At ratios below 1 , the biomass content only has a minor influence on conversion efficiency. Furthermore, higher biomass contents tend to generate products with higher viscosities which could be a limiting factor for successful utilization in heat engines.

Liquefaction time: Short reaction times result in low biomass to liquid conversion efficiency. The reason for this lies in only partial depolymerization of the lignin and the cellulose. Contrarily, when reaction time is prolonged beyond the optimal point, solid residue starts to form as a consequence of recondensation reactions taking place between degradation products of cellulose and lignin, as mentioned above. This clearly indicates the importance of accurately defined reaction time in combination with upper two parameters.

Considering the above limitations, three different types of LW (presented also in Fig. 2) were produced in a $200 \mathrm{~L}$ batch reactor and tested in a gas turbine. Based on feedstock availability, two main constituents of the fuel were selected as spruce wood and glycerol. Di-ethylene glycol was also added to lower viscosity of the fuel [11]. Due to the wide availability of lignocellulosic waste and glycerol (large amounts of residual glycerol are produced by trans esterification of vegetable and animal fats to biodiesel), the content of these two components was maximized in accordance to limitations of the process, process conditions and end product physiochemical properties. Wood and glycerol content is therefore limited to $33 \%$, which is in line with current stage of research and relatively novel approach to fuel production. The solvent was thus prepared with identical shares of glycerol and di-ethylene glycol to ensure sufficiently low viscosity of the fuel. $3 \% \mathrm{TsOH}$ acid was added as a catalyst.
Spruce wood with particle size up to $3 \mathrm{~mm}$ was added to the solvent. The mixture was heated to $180{ }^{\circ} \mathrm{C}$ and constantly mixed for 180 minutes. The analyzed LW compositions are explained in the following sections.

\subsubsection{LW Type no. 1}

$36.38 \%$ glycerol; $36.38 \%$ diethylene glycol; $2.25 \%$ $\mathrm{TsOH} ; 25 \%$ wood. This type was previously tested in [11] and it is used here to show the influence of LW composition on exhaust emissions. It yields relatively low viscosity of $80 \mathrm{cSt}$ at $100^{\circ} \mathrm{C}$ (see Fig. 1) and low $\mathrm{pH}$ value. The evaluation of emissions characteristics in the measured points was repeated in the series of experiment presented in this study to avoid the influence of deviations in ambient conditions and minor changes in the experimental setup.

Table 2. Elemental composition of $L W$ with $25 \%$ wood content

\begin{tabular}{|c|c|c|c|}
\hline Property & Value & Property & Value \\
\hline C [wt.\%] & 47.60 & S [wt.\%] & 0.89 \\
\hline $\mathrm{H}$ [wt.\%] & 7.98 & 0 [wt.\%] & 43.34 \\
\hline N [wt.\%] & 0.19 & $\mathrm{pH}$ value & 2.5 \\
\hline \multicolumn{2}{|c|}{ Stoichiometric ratio } & & $6.8: 1$ \\
\hline \multicolumn{2}{|c|}{ Density $[\mathrm{kg} / \mathrm{L}]$} & & 1.30 \\
\hline \multicolumn{2}{|c|}{ LHV [MJ/kg] } & & 20.2 \\
\hline \multicolumn{2}{|c|}{ Viscosity at $100^{\circ} \mathrm{C}$} & & $80 \mathrm{cSt}$ \\
\hline
\end{tabular}

\subsubsection{LW Type no. 2}

$32.33 \%$ glycerol; $32.33 \%$ diethylene glycol; $2.00 \%$ TsOH; $33 \%$ wood. This type features lower feedstock costs. The increased proportion of wood is still within the allowed limitations of the liquefaction process, however it raises the viscosity of the fuel, which is nearly 2 times higher $\left(171 \mathrm{cSt}\right.$ at $\left.100{ }^{\circ} \mathrm{C}\right)$ than for aforementioned type with $25 \%$ wood content, as shown in Fig. 1. This is the consequence of higher amount of lignin and cellulose degradation products with higher molecular weights. The viscosity of D2 diesel fuel is also shown for the purpose of comparison. The elemental composition and thus also the heating value of LW type no. 1 are very similar to the ones of the LW type no. 2. This is mainly due to the almost identical elemental ratio of $\mathrm{O} / \mathrm{C}$ and $\mathrm{H} / \mathrm{C}$ of glycols and wood. 


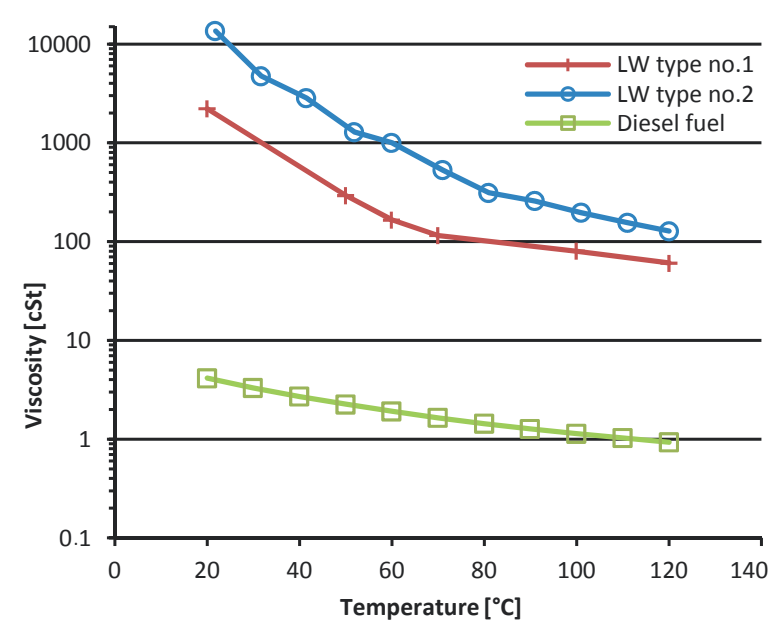

Fig. 1. Viscosity of $D 2$ and $L W$ with 33 and $25 \%$ wood content

\subsubsection{LW Type no. 3}

$36.38 \%$ glycerol; $36.38 \%$ di-ethylene glycol; $2.25 \%$ $\mathrm{TsOH}, 25 \%$ wood, $0.71 \% \mathrm{NH}_{4} \mathrm{OH}$. The basis for this LW type is the reactant ratio used in LW type no. 1, partially neutralized by the addition of ammonium hydroxide. Partial neutralization of the acid catalyst has a beneficial effect on corrosivity of the fuel which effectively broadens the selection of fuel system materials to lower grade stainless steels. In addition, partially neutralized acid catalyst shifts the liquefaction reaction threshold to higher temperatures and by this increases the stability of the fuel. Undesirable effects that are experienced due to the presence of alkali metals in the fuels for the turbine engines (i.e. ash and slug formation) were the main driver for avoiding other bases such as $\mathrm{NaOH}$ or $\mathrm{KOH}$ and thus favoring $\mathrm{NH}_{4} \mathrm{OH}$.

Table 3. Elemental composition of LW with $25 \%$ wood content and elevated $\mathrm{pH}$ value

\begin{tabular}{|c|c|c|c|}
\hline Property & Value & Property & Value \\
\hline C [wt.\%] & 47.52 & S [wt.\%] & 0.89 \\
\hline $\mathrm{H}$ [wt.\%] & 8.00 & 0 [wt.\%] & 43.26 \\
\hline $\mathrm{N}$ [wt.\%] & 0.34 & $\mathrm{pH}$ value & 5.5 \\
\hline \multicolumn{2}{|c|}{ Stoichiometric ratio } & & $6.8: 1$ \\
\hline \multicolumn{2}{|c|}{ Density $[\mathrm{kg} / \mathrm{L}]$} & & 1.30 \\
\hline \multicolumn{2}{|c|}{ LHV [MJ/kg] } & & 20.2 \\
\hline \multicolumn{3}{|c|}{ Viscosity at $100^{\circ} \mathrm{C}$} & $80 \mathrm{cSt}$ \\
\hline
\end{tabular}

The addition of ammonium hydroxide slightly altered the elemental composition of the fuel due to added nitrogen, however, the molecular composition remained almost unchanged, thus the viscosity was the same as for LW type no. $1\left(80 \mathrm{cSt}\right.$ at $\left.100{ }^{\circ} \mathrm{C}\right)$. By the addition of $0.71 \%$ of $25 \%$ ammonia solution, the $\mathrm{pH}$ value of LW type no. 1 was increased from 2.5 to 5.5 to mimic diesel fuel.

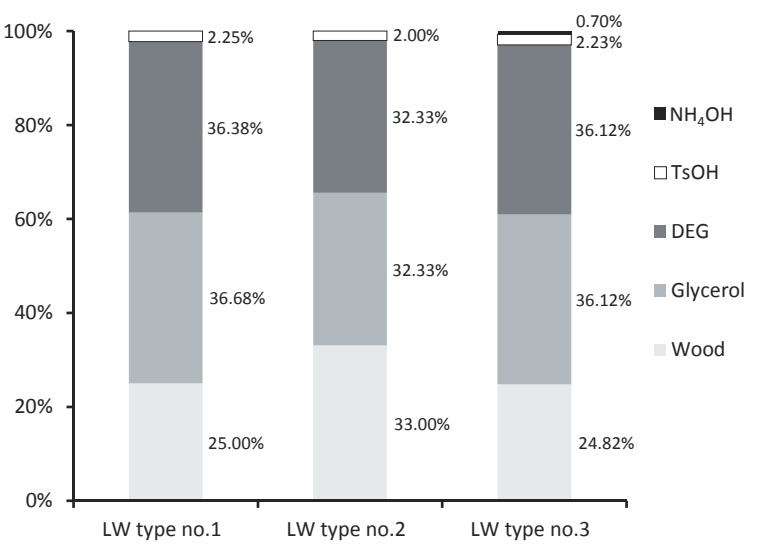

Fig. 2. Composition of different tested LW types

\section{METHODS}

Combustion research was performed on an experimental turbine presented in [11]. For the purpose of this study, the fuel preheating system was upgraded with pre-filtering elements, designed to withstand the increased viscosity of LW type no. 2. Adaptation to increased viscosity was also performed on the piping and pumps. This was of particular importance to enable cold starting of the fuel system, where sufficiently low pressure losses were required (viscosities at room temperatures were roughly 3000 cSt for LW type no. 1 and 14000 cSt for LW type no. 2). The system was therefore capable of handling heavy and corrosive fuels and able to achieve required range of fuel flows (14 to $19 \mathrm{~kg} / \mathrm{h}$ ) and supply pressures ( 2.3 to $2.7 \mathrm{bar}$ ). Piping connection to the gas turbine was achieved through a three-way valve. This three-way valve allows utilization of the diesel fuel while starting and stopping the gas turbine.

Data were collected at three different turbine inlet temperatures (TIT) for each LW type; 750, 800 and $850{ }^{\circ} \mathrm{C}$. These TIT values were achieved by altering the fuel mass flow. TIT was therefore a steered parameter, whereas air flow, EQR, pressure ratio and primary air temperature were the dependent variables. Based on the conclusions of the study in [11], fuel preheat temperature was kept constant at $100{ }^{\circ} \mathrm{C}$. Higher preheating temperatures exhibited proneness to formation of carbon deposit on nozzle discharge surfaces due to accelerated thermal degradation of the fuel. This causes an off center spray pattern, which results in carbon buildup on combustion chamber 
walls and thus in excessive $\mathrm{CO}$ emission and impaired operational stability, being highly undesirable.

The experimental system was equipped with the following. The fuel preheater had K-type thermocouples, PT-100 RTDs, coriolis mass flow meter and capacitive pressure sensors to closely monitor the conditions that fuel was exposed to. The gas turbine used K-type thermocouples, capacitive pressure sensors, laminar flow meter and emission measuring hardware to characterize the operating point and combustion process. An exhaust gas sample $(\sim 3 \mathrm{~L} / \mathrm{min})$ was continuously pumped through a heated line $\left(190^{\circ} \mathrm{C}\right)$ to FID, NDIR and CLD detectors to avoid any condensation of hydrocarbons or water vapor. Measured emissions values were postprocessed and translated from measured volume concentrations to concentrations corrected to $15 \% \mathrm{O}_{2}$ in exhaust gasses by Eq. (1). This was done to remove the ambiguities linked to different EQR in different operating points. This is also a widespread practice to specify the permissible emission levels [18].

$$
\varnothing_{\mathrm{i} 15 \% \mathrm{O}_{2} \text { exh }}=\varnothing_{\mathrm{i}} \frac{\mathrm{EQR}_{15 \% \mathrm{O}_{2} \text { exh }}}{\mathrm{EQR}_{\mathrm{i}}} \text {. }
$$

\section{RESULTS AND DISCUSSION}

The main scope of the study was to determine the influence of different LW types on emission trends and underlying formation mechanisms, basing on acquired thermodynamic and exhaust gas composition data. Interdependencies between known fuel compositions and gaseous emissions were then defined and explained. To provide benchmark thermodynamic and emissions results, conventional diesel fuel was used.

First, the emissions and thermodynamic parameters of each LW type are analyzed separately to enlighten the interaction between the emission formation phenomena and chemical and physical properties of different types of LWs. This will be followed by a comparison of emission concentrations for all LW types with added results of a benchmark diesel fuel.

\subsection{LW Type no. 1}

It is clearly discernible from Fig. 3 that $\mathrm{CO}$ and THC emissions substantially decrease with increasing TIT, whereas $\mathrm{NO}_{\mathrm{x}}$ emissions increase with TIT. This opposing trend can be explained by the molecular composition of the fuel. One of the main wood constituents is the lignin which in comparison to cellulose contains high number of cyclic structures in its basic monomers [19]. Generally, the liquefaction process depolymerizes lignin into its basic monomersmonolignols (i.e. p-coumaryl alcohol, coniferyl alcohol, sinapyl alcohol [16]) which still contain an aromatic ring that usually requires high activation energy to form combustion supporting radicals. Thus, high dependency of $\mathrm{CO}$ emissions on TIT is mainly related to the fact that large amount of species with high autoignition temperature do not reach their temperature threshold to dissociate or are dissociated too late in the primary zone, causing an insufficient residence time of the mixture. Increasing TIT is thus clearly beneficial in reducing $\mathrm{CO}$ and THC emissions - the overall temperature field in combustion chamber is shifted towards higher temperatures which slightly postpones the reaction quenching and effectively helps to reduce the emissions of intermediate combustion species.

An additional mechanism that contributes to reduced $\mathrm{CO}$ emissions at high TIT is increased turbulence in the primary zone, which is predominantly caused by higher volumetric flows of the air (Fig. 4). Increased turbulent kinetic energy increases the rate of spray evaporation and mixture preparation. Despite a relatively low LHV and high viscosity, the $\mathrm{CO}$ emissions can be considered as relatively low for this fuel. This is to a large extent related to the high oxygen content of LW. It can substantially increase the mixture homogeneity if sufficient dissociation is achieved as $22 \%$ of stoichiometric oxygen is available through the fuel bound oxygen atoms. This favors formation of $\mathrm{OH}$ radicals, which are the essential species for $\mathrm{CO}$ oxidation reactions [20]. High oxygen content is perceived also through low stoichiometric ratio of LW which is only 6.8 .

Mechanisms of THC emissions are similar to those of $\mathrm{CO}$ and therefore usually follow the same trends. They consist of only partially dissociated fuel molecules and are therefore a preceding step before $\mathrm{CO}$ formation occurs. They most likely originate from highly temperature resistant hydrocarbons and undesirable reaction quenching in cold spots of the combustion chamber.

Unlike $\mathrm{CO}$ and $\mathrm{THC}, \mathrm{NO}_{\mathrm{x}}$ concentrations slightly increased with increasing TIT. This is in-line with Zeldovich $\mathrm{NO}_{\mathrm{x}}$ formation mechanism, where higher temperatures in primary zone cause the $\mathrm{N}_{2}$ molecule to dissociate into atomic state and then further oxidize to $\mathrm{NO}$ and/or $\mathrm{NO}_{2}$. With its high activation energy, the separation of $\mathrm{N}$ from $\mathrm{N}_{2}$ occurs only at very high temperatures (over $1600{ }^{\circ} \mathrm{C}$ ) [21] and is therefore favored only in the immediate vicinity of the flame 
zone. However, it is believed that the major component of $\mathrm{NO}_{\mathrm{x}}$ emissions in gas turbines is the Fenimore $\mathrm{NO}_{\mathrm{x}}$ mechanism, which originates from reactions of $\mathrm{HCN}$ and $\mathrm{CN}$ radicals with oxygen. The Fenimore mechanism features high rates in the areas exhibiting relatively low temperature $\left(\sim 700{ }^{\circ} \mathrm{C}\right)$ and fuel-rich conditions [20]. Its sensitivity to TIT is thereby linked to EQR elevation at high TIT and thus richer conditions in primary combustion chamber zone. With larger quantity of delivered fuel, the amount of FBN (fuel bound nitrogen) is also increased. An increased amount of FBN contributes to higher $\mathrm{NO}_{\mathrm{x}}$ emissions although this effect is not visible in the presented charts as the correction to $15 \% \mathrm{O}_{2}$ is applied to the measured data. The overall perceivable $\mathrm{NO}_{\mathrm{x}}$ increase is therefore a combination of two mechanisms Zeldovich and Fenimore $\mathrm{NO}_{\mathrm{x}}$. These two are believed to have a major influence and this trend is observed also if no correction to the measured data is applied.

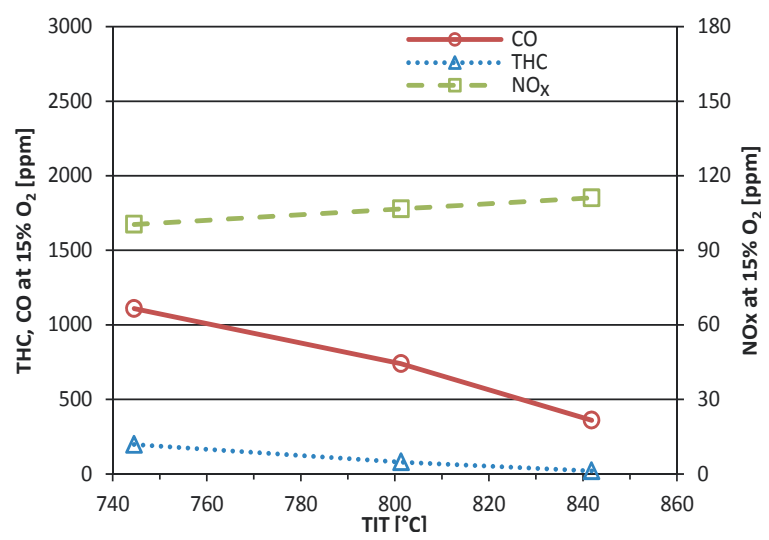

Fig. 3. Emissions, corrected to $15 \% \mathrm{O}_{2}$ for $\mathrm{LW}$ with $25 \%$ wood content

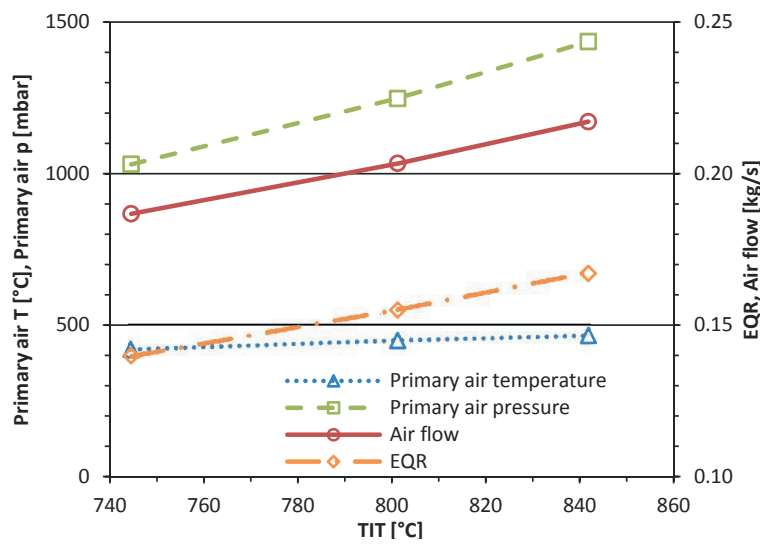

Fig. 4. Operating parameters of experimental system firing $L W$ with $25 \%$ wood content

\subsection{LW Type no. 2}

The increased wood content (by 8\%) in this type of LW is manifested mainly through altered molecular composition. The elemental composition and thus also heating value remains unchanged due to very similar elemental compositions of glycols and lignocellulosic biomass. Perceivable differences in LHV and elemental ratio would be visible only if very large changes in reactant ratios would be made. As a larger amount of monolignols is contained in LW type no. 2 , increased share of cyclic hydrocarbon molecules could slightly increase ignition resistance of the LW. Generally, a higher number of molecules with larger molecular mass in comparison to LW type no. 1 with $25 \%$ wood content also lead to higher viscosity ( 80 cSt for $25 \%$ wood content and $171 \mathrm{cSt}$ for $33 \%$ wood content) which significantly influences atomization ability. Decreased evaporation rate is the consequence of larger initial droplet diameters and altered evaporation curve of the fuel. These two mechanisms are the main reason for late formation of the mixture and thus a main driver of a significant increase of $\mathrm{CO}$ and THC emissions compared to those of LW type no. 1 presented in section 3.1. Larger droplet diameter contributes to the increased spray penetration depth and lower evaporation rates. Both mechanisms extend combustion into the secondary combustion chamber zone. Here, lower temperatures and lower local EQR could impede final oxidation stage of carbon and hydrocarbon molecules leading to increased $\mathrm{CO}$ and THC emissions. As mentioned above, another aspect of altered molecular composition is its cyclic hydrocarbon content. It is anticipated that even if the viscosity of LW with $33 \%$ wood content would be the same as for LW with $25 \%$ wood content, $\mathrm{CO}$ and THC emissions would still be higher due to increased content of monolignols and their high ignition resistance. Elevated $\mathrm{CO}$ and THC emissions are therefore a consequence of altered molecular composition which influences the combustion process in two ways: a) by impairing the atomization process and b) by increasing ignition resistance of the mixture.

$\mathrm{NO}_{\mathrm{x}}$ emissions of LW type no. 2 are lower by approximately $20 \mathrm{ppm}$ compared to those of LW type no. 1 at lower TIT (Fig. 5). In the upper TIT end, this reduction is slightly lower; roughly $10 \mathrm{ppm}$. The sensitivity of LW composition on $\mathrm{NO}_{\mathrm{x}}$ reduction mechanisms is therefore declining with increasing TIT and thus the influence of all three mechanisms on this sensitivity is analyzed subsequently. Focusing on FBN, its content should be roughly $8 \%$ higher as the only source of nitrogen is wood feedstock 
which is in the case of analyzed LW type increased by $8 \%$. Contribution to cumulative $\mathrm{NO}_{\mathrm{x}}$ is therefore in the range of 4 to $8 \mathrm{ppm}$. The exact numbers were acquired through equilibrium equations for complete combustion assuming a $1 / 3$ and 2/3 efficiency of FBN conversion to $\mathrm{NO}_{\mathrm{x}}$; these rates were chosen based on conversion efficiencies of FBN determined in the next section. Partial reduction of $\mathrm{NO}_{\mathrm{x}}$ emissions when comparing them to those of LW with $25 \%$ wood content arises from aforementioned postponed combustion and lower flame temperatures due to lower local EQR as described above. The reduction of $\mathrm{NO}_{\mathrm{x}}$ concentrations is therefore a consequence of suppressed Zeldovich mechanism due to lower temperatures and also suppressed Fenimore mechanisms due to lower EQR ratios. Considering that Fenimore mechanism has a relatively low activation energy and is maintained even in the areas where temperatures are as low as $700{ }^{\circ} \mathrm{C}$ [20], the main cause for reduction of Fenimore $\mathrm{NO}_{\mathrm{x}}$ component is most likely lower local EQR ratio and not the lower temperature as in the case of the Zeldovich component.

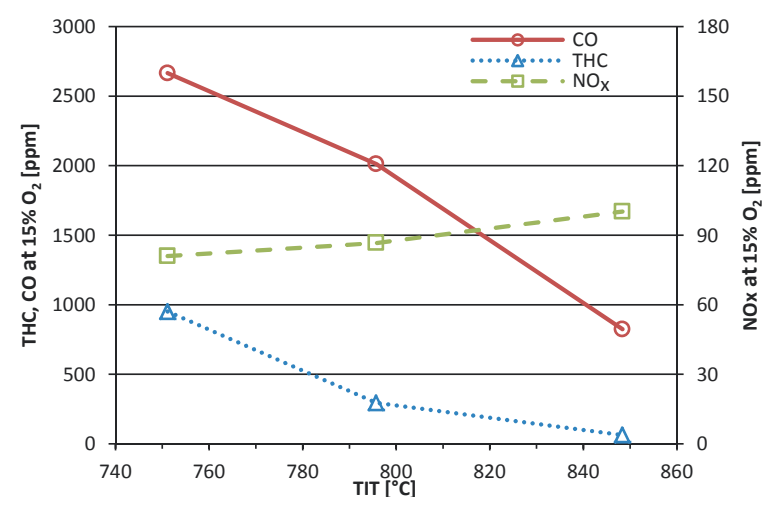

Fig. 5. Emissions, corrected to $15 \% \mathrm{O}_{2}$ for $\mathrm{LW}$ with $33 \%$ wood content

Focusing on the upper explanations it can be summarized that the main drivers for reduced $\mathrm{NO}_{\mathrm{x}}$ concentrations of the LW with increased content of wood are: 1) the combustion chamber temperature. 2) the flow field which is significantly influenced by different fuel properties and influences $\mathrm{NO}_{\mathrm{x}}$ formation mechanisms, and 3) $\mathrm{NO}_{\mathrm{x}}$ formation paths as explained above. This, however, does not alter the global thermodynamic parameters as they closely resemble those exhibited by LW type no. 1 as is evident from Fig. 6. Since water content was not analyzed, some of $\mathrm{NO}_{\mathrm{x}}$ reduction could also be attributed to higher water content of LW type no. 2, which can be related to a higher share of a lignocellulosic material in the fuel.

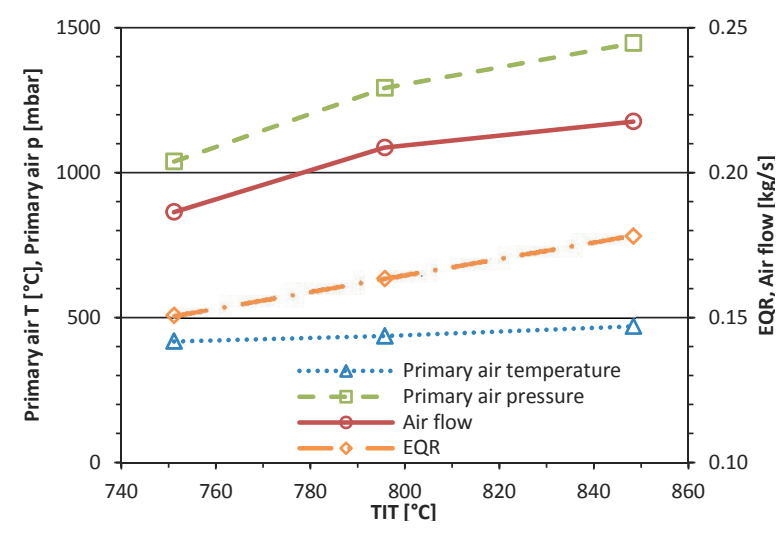

Fig. 6. Operating parameters of experimental system firing $L W$ with $33 \%$ wood content

\subsection{LW Type no. 3}

Thermodynamic parameters of the experimental turbine remained unchanged also with LW type no. 3 as visible in Fig. 8, thus providing comparable conditions to LW type no. 1 and no. 2. When observing emissions concentrations in Fig. 7, the hypothesis that addition of ammonia and change in $\mathrm{pH}$ value of the fuel will not affect $\mathrm{CO}$ and THC emissions is clearly confirmed, since the emissions concentrations and their trends are almost the same as those with LW type no. 1. The reason for this lies in the negligible influence of partial neutralization on molecular composition: a) atomization quality is not affected by change in viscosity or surface tension as these properties are not affected by neutralization and $b$ ) the addition of ammonia does not alter the evaporation curve of the LW. The local EQR ratios of the mixture, air temperatures and oxidation kinetics of hydrocarbon molecules are therefore very close to those encountered with the LW type no. 1.

More pronounced differences are perceivable in $\mathrm{NO}_{\mathrm{x}}$ concentrations which are elevated by roughly 30 ppm over the entire TIT interval. This nearly constant shift to higher values supports the hypothesis that $\mathrm{NO}_{\mathrm{x}}$ emissions trends are the same as those of LW type no. 1, although the absolute value of emissions is elevated. This increase in $\mathrm{NO}_{\mathrm{x}}$ emissions is mainly related to conversion of $\mathrm{FBN}$ to $\mathrm{NO}_{\mathrm{x}}$. This is reasoned by the fact that this mechanism is usually almost insensitive to EQR and temperature field, whereas it is clearly supported by the elevated nitrogen share in the fuel. There are strong indications that Zeldovich and Fenimore contributions to the overall $\mathrm{NO}_{\mathrm{x}}$ emissions are nearly identical for the LW type nos. 1 and 3 . This is reasoned by the fact that TIT and global EQR of 
these two LW types are identical, and furthermore nearly identical CO and THC emissions also indicate very similar temperature and concentration field within the combustion chamber. Therefore it is believed that the difference in $\mathrm{NO}_{\mathrm{x}}$ emissions is the consequence of increased amount of FBN to $\mathrm{NO}_{\mathrm{x}}$ conversion. Calculation revealed that $0.1 \mathrm{~mol} / \mathrm{L}$ of nitrogen was added to the LW with $25 \%$ wood content to produce LW type no. 3. This effectively increased the share of FBN almost by a factor of 2 . As stated in [20], conversion efficiency from $F B N$ to $\mathrm{NO}_{\mathrm{x}}$ is around $2 / 3$ for some types of fuels (propane with 2500 ppm addition of methylamine).

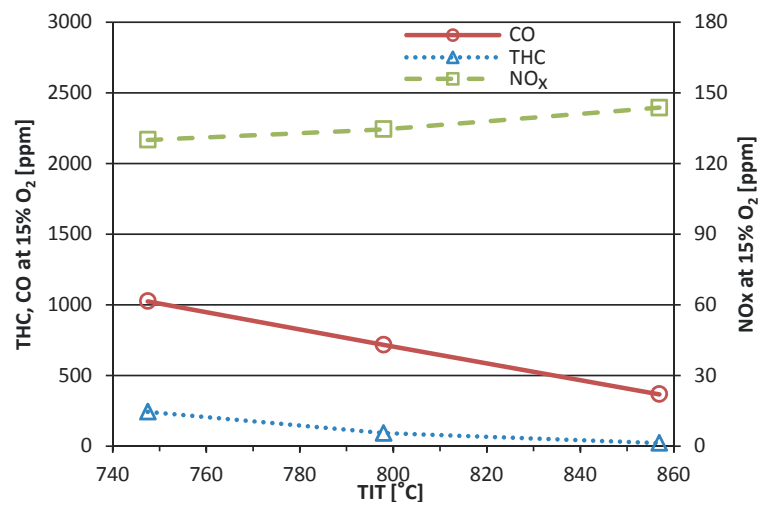

Fig. 7. Emissions, corrected to $15 \% 02$ for $L W$ with $25 \%$ wood content and elevated $\mathrm{pH}$ value

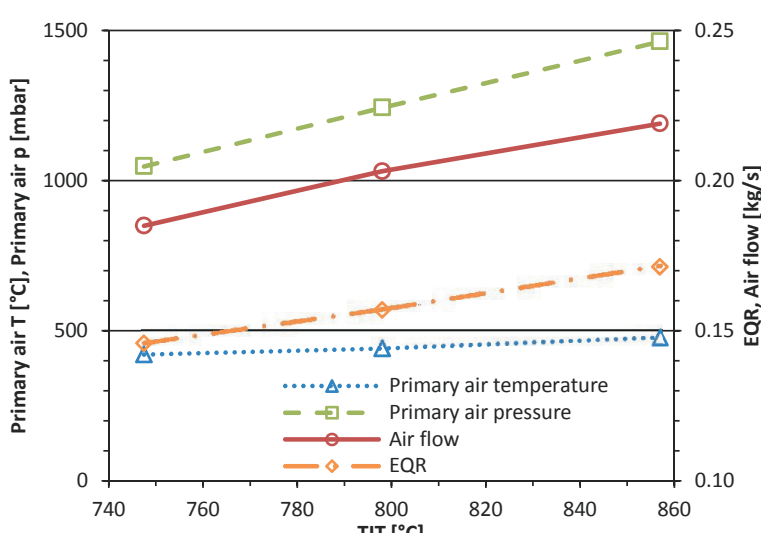

Fig. 8. Operating parameters of experimental system firing $L W$ with $25 \%$ wood content and elevated $\mathrm{pH}$ value

This can be compared with the conversion rate of the FBN to $\mathrm{NO}_{\mathrm{x}}$ when firing LW type no. 3, assuming that $\mathrm{FBN}$ to $\mathrm{NO}_{\mathrm{x}}$ is the only contributing mechanism to the difference in $\mathrm{NO}_{\mathrm{x}}$ between LW type no. 1 and 3. In this case it can be calculated that conversion efficiency of $\mathrm{FBN}$ to $\mathrm{NO}_{\mathrm{x}}$ when firing LW in aforementioned conditions is roughly $1 / 3$ (i.e. $33 \%$ ). Clearly, nitrogen bound in wood decomposition products or nitrogen added through ammonium hydroxide could exhibit different combustion kinetics and thus also different conversion efficiencies to $\mathrm{NO}_{\mathrm{x}}$. This could cause a large discrepancy between predicted and actual FBN conversion efficiency so the proposed $33 \% \mathrm{FBN}$ to $\mathrm{NO}_{\mathrm{x}}$ efficiency should only be used as a rough estimate under similar conditions to those employed in this study. It was, however, already proven in [21] that high $\mathrm{O} / \mathrm{N}$ ratio in fuels could reduce FBN conversion efficiency. This thesis is supported by the high oxygen content of LW and the measured data.

\subsection{Influence of Fuel Type on Emissions}

In this section, emissions for each of the tested fuels are given. The results are grouped by emission species to illuminate the influence of fuel type on each of the emission species. Thermodynamic parameters of operation with diesel fuel were very close to those of all LW types to assure comparable conditions in combustion chamber in terms of airflow, temperature and pressure.

In Fig. 9, $\mathrm{CO}$ emissions are shown. Trends are in line with phenomena explained above and can be mainly attributed to:

a) viscosity of the fuels (with LW type no. 2 having the highest, followed by LW type no. 1 and no. 3 and significantly lower viscosity of diesel fuel);

b) density of the fuels (with all LW types having higher density than diesel fuel by roughly a factor of 1.5);

c) molecular composition of the fuels (with LW type no. 2 having higher content of cyclic hydrocarbons than LW type no. 1 and no. 3 and all LW types having higher molecular weights than diesel fuel).

Atomization of LW is most likely notably impaired by a) and penetration depth is further increased by b). The combination of these two facts reduces surface to mass ratio of the droplets which is most likely together with c) the reason for reduced evaporation rate of the fuel. Besides decreased volatility due to heavier molecular weights, c) also influences the combustion process due to cyclic hydrocarbon content with its high ignition resistance. The CO emissions are therefore the highest with LW type no. 2, followed by LW type no. 1 and LW type no. 3. The latter two exhibit similar concentrations due to similar properties under a), b) and c). With diesel fuel, very low concentrations were achieved due to more favorable physical and chemical characteristics of diesel in comparison to all LW types allowing for fast 
mixture formation and very low rate of mixture escape into colder parts of combustion chamber.

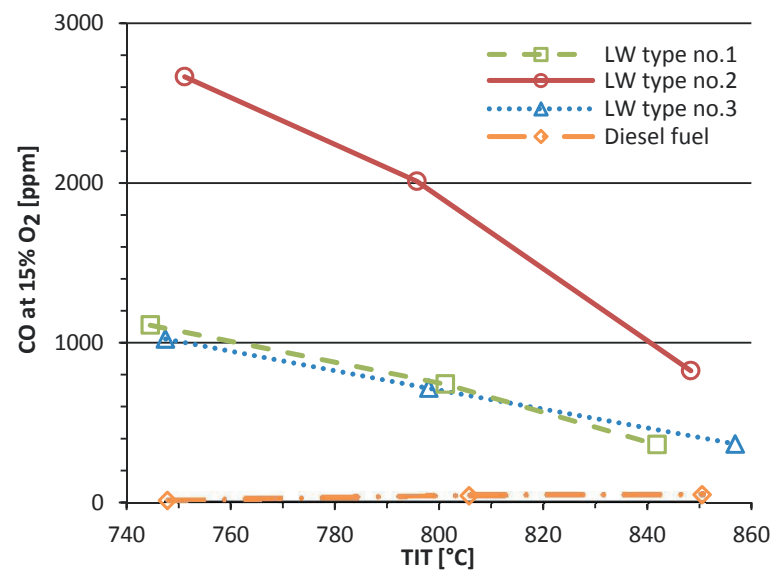

Fig. 9. CO emissions for different LW types

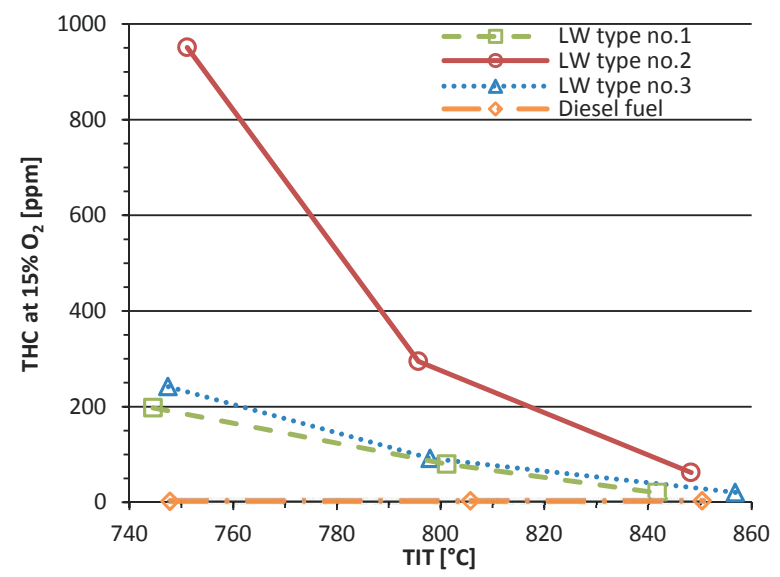

Fig. 10. THC emissions for different $L W$ types

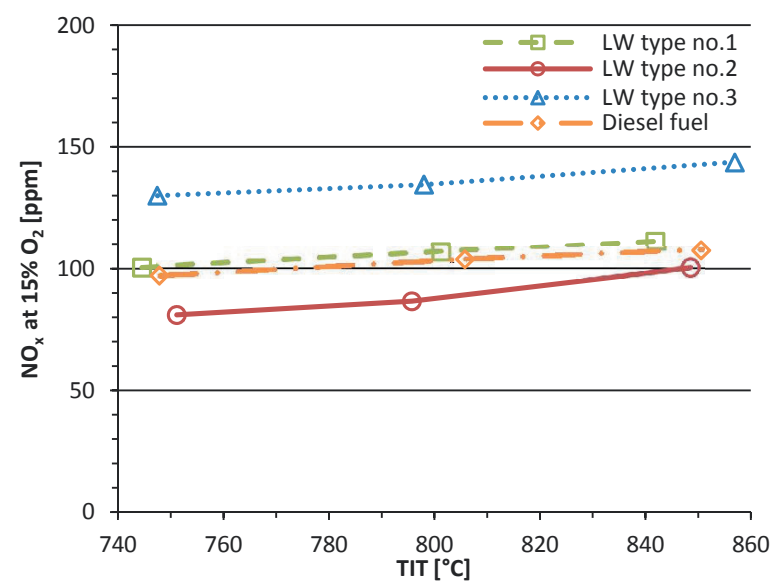

Fig. 11. $\mathrm{NO}_{x}$ emissions for different $L W$ types

Similar trends are visible for THC emissions in Fig. 10, confirming the hypothesis that formation of unburned hydrocarbons is influenced by the same phenomena as formation of CO. Again, very low concentrations were measured with diesel fuel, as the density, viscosity and volatility favour much faster mixture formation and thus a lower rate of combustion reaction quenching in cold parts of the combustion chamber (namely cooling and dilution air).

$\mathrm{NO}_{\mathrm{x}}$ emissions are presented in Fig. 11, with emissions of LW no. 3 being the highest, followed by LW type no.1 and diesel fuel. The lowest concentrations are observed with LW type no. 2. The results support the aforementioned influences of FBN and temperature field on $\mathrm{NO}_{\mathrm{x}}$ formation mechanisms, with high FBN content promoting $\mathrm{NO}_{\mathrm{x}}$ formation as in the case of LW type no. 3 and reduced $\mathrm{NO}_{\mathrm{x}}$ formation rate with LW type no. 2 due to postponed mixture formation and thus lower flame temperatures.

\section{CONCLUSIONS}

Three different types of lignocellulosic biofuel were tested in a gas turbine to investigate the effects of increased wood content and altered $\mathrm{pH}$ value of the fuel on the emissions of $\mathrm{CO}, \mathrm{THC}$ and $\mathrm{NO}_{\mathrm{x}}$. Results indicated that combustion process is strongly affected by content of lignocellulosic material, while the effect of partial neutralization is isolated to influence on $\mathrm{NO}_{\mathrm{x}}$ emissions. The emission characteristics of the LW types were as follows.

LW type no. 1: It exhibited relatively high $\mathrm{CO}$ and THC emissions, highly dependent on TIT in comparison to emissions of a diesel fuel. In literature, this was attributed to specific molecular composition and cyclic hydrocarbon content as well as viscosity and density. NOx emissions showed increasing trend over TIT where increase in Zeldovich and Fenimore mechanisms of NOx formation is believed to have a major role.

LW type no. 2: $\mathrm{CO}$ and THC emissions increased in comparison to LW type no. 1 as a consequence of higher wood content. The reason for this is altered molecular composition of the fuel, resulting in viscosity increase and subsequent deterioration of atomization quality. $\mathrm{NO}_{\mathrm{x}}$ emissions are slightly reduced due to altered flow and temperature field, caused by reduced mixture formation rate and consequent local EQR ratios.

LW type no. 3: $\mathrm{CO}$ and $\mathrm{THC}$ emissionswere very similar to LW type no. 1. However, partial neutralization was found to influence $\mathrm{NO}_{\mathrm{x}}$ emissions. An increase of $30 \mathrm{ppm}$ was visible over entire operating range of the turbine which was accounted to increased FBN originating from ammonia-borne nitrogen. The conversion of FBN to $\mathrm{NO}_{\mathrm{x}}$ was found 
to be roughly $33 \%$. CO and THC emissions were unchanged in comparison to LW type no. 1, confirming the hypothesis that partial neutralization does not influence the oxidation kinetics of hydrocarbon molecules.

Diesel fuel: Absolute values of emissions were significantly lower (by an order of magnitude) for $\mathrm{CO}$ and THC. This is in line with physical and chemical characteristics of different LW types which have unfavorable influence on the combustion process mainly because of delayed mixture formation and influence of cyclic hydrocarbons on combustion kinetics. $\mathrm{NO}_{\mathrm{x}}$ emissions are comparable to LW type no. 1 .

Despite the elevated $\mathrm{CO}$ and $\mathrm{THC}$ emissions, LW type no. 2 exhibits promising trends as these emissions significantly reduce with increasing TIT. Moreover, they would most likely further reduce if more a advanced gas turbine with higher TIT were used. An adapted combustion chamber geometry could further help to prevent excessive mixture escape into the secondary combustion chamber zone. Additionally, the low impact of added base in LW with $25 \%$ wood content on combustion and emissions could greatly improve the applicability of such fuel in gas turbines by reducing the costs for fuel processing systems and possibly filtration methods without impeding combustion performance and $\mathrm{CO}$ emissions, while moderately increasing $\mathrm{NO}_{\mathrm{x}}$ emissions.

\section{ACKNOWLEDGEMENTS}

The authors acknowledge the financial support from the Ministry of Education, Science, Culture and Sport of the Republic of Slovenia through the contract no. 3211-10-000057 (Centre of excellence Polymer Materials and Technologies), University of Ljubljana for support through Innovative Scheme, contract no. 323 and finally to Slovenian Research Agency for support through contract no. L2-5468.

\section{NOMENCLATURE}

$\begin{array}{ll}\mathrm{D} 2 & \text { Diesel fuel } \\ \mathrm{LW} & \text { Liquefied wood } \\ \mathrm{CO} & \text { Carbon monoxide } \\ \mathrm{THC} & \text { Total hydrocarbons } \\ \mathrm{NO}_{\mathrm{x}} & \text { Nitrous oxides } \\ \mathrm{LW} & \text { Liquefied wood } \\ \mathrm{H}_{2} \mathrm{SO}_{4} & \text { Sulfuric acid } \\ \mathrm{TsOH} & \text { Tossylic acid } \\ \mathrm{LHV} & \text { Lower heating value } \\ \mathrm{NH}_{4} \mathrm{OH} & \text { Ammonium hydroxide }\end{array}$

FBN Fuel bound nitrogen

FID Flame ionization detector

NDIR Nondispersive infrared

CLD Chemiluminiscence detector

TIT Turbine inlet temperature

$\varnothing_{\mathrm{i}} \quad$ Measured concentrations

$\varnothing_{\mathrm{i} 15 \% \mathrm{O}_{2} \text { exh }}$ Corrected concentrations to $15 \% \mathrm{O}_{2}$

EQR Equivalence ratio

$\mathrm{EQR}_{\mathrm{i}} \quad$ Measured equivalence ratio

$\mathrm{EQR}_{\mathrm{i} 15 \% \mathrm{O}_{2} \text { exh }}$ Equivalence ratio at $15 \% \mathrm{O}_{2}$

\section{REFERENCES}

[1] Hribernik, A., Kegl, B. (2007). The influence of biodiesel on the combustion and emission characteristics of a diesel engine. Strojniški vestnik - Journal of Mechanical Engineering, vol. 53, no. 10, p. 683-695.

[2] Demirbas, A. (2011). Competitive liquid biofuels from biomass. Applied Energy, vol. 88, no 1, p. 17-28, DOI:10.1016/j.apenergy.2010.07.016.

[3] Stritih, U., Zupan, G., Butala, V. (2007). A parametrical analysis of a biomass stirling cogeneration unit for use in housing. Strojniški vestnik - Journal of Mechanical Engineering, vol. 53, no. 9, p. 556-568.

[4] Mabee, W.E., McFarlane, P.N., Saddler, J.N. (2011). Biomass availability for lignocellulosic ethanol production. Biomass and Bioenergy, vol. 35, no. 11, p. 4519-4529, DOI:10.1016/j. biombioe.2011.06.026.

[5] Chiaramonti, D., Oasmaa, A., Solantausta, Y. (2005). Power generation using fast pyrolysis liquids from biomass. Renewable and Sustainable Energy Reviews, vol. 11, no. 6, p. 1056-1086, DOI:10.1016/j.rser.2005.07.008.

[6] Mohan, D., Pittman, C.U., Steele, P.H. (2006). Pyrolysis of wood/biomass for bio-oil: A critical review. Energy \& Fuels, vol. 20, no. 3, p. 848889, DOI:10.1021/ef0502397.

[7] Hossain, A.K., Davies, P.A. (2013). Pyrolysis liquids and gases as alternative fuels in internal combustion engines - A review. Renewable and Sustainable Energy Reviews, vol. 21, p. 168-189, DOI:10.1016/j.rser.2012.12.031.

[8] Behrendt, F., Neubauer, Y., Oevermann, M., Wilmes, B., Zobel, N. (2008). Direct liquefaction of biomass - a review. Chemical Engineering Technology, vol. 31, no. 5, p. 667-677, DOI:10.1002/ceat.200800077. 
[9] Rezzoug, S., Cappart, R. (1996). Solvolysis and catalytic hydrotreatement of wood to provide fuel. Biomass and Bioenergy, vol. 11, p. 343-352, DOI:10.1016/0961-9534(96)00025-6.

[10]Rezzoug, S., Cappart, R. (2002). Liquefaction of wood in two successive steps: solvolysis and catalytic hydrotreatement. Applied Energy, vol. 72, no. 4-5, p. 631-644, DOI:10.1016/S03062619(02)00054-5.

[11]Seljak, T., Rodman Oprešnik, S., Kunaver, M., Katrašnik, T. (2012). Liquefied lignocellulosic material as a fuel for gas turbines. Applied Energy, vol. 99, p. 40-49, DOI:10.1016/j. apenergy.2012.04.043.

[12]Kunaver, M., Čuk, N., Jasiukaityté, E., Kovač, F., Rodman Oprešnik, S., Katrašnik, T. (2010). Method of producing fuel by liquefaction of cellulose-containing solid materials. European pat. appl. no. 11003655.5. Centre of Excellence PoliMat. Ljubljana.

[13]Kobayashi, M., Asano, T., Kajiyama, M., Tomita, B. (2004). Analysis on residue formation during wood liquefaction with polyhydric alcohol. Journal of Wood Science, vol. 50, no. 5, p. 407414, DOI:10.1007/s10086-003-0596-9.

[14]Yamada, T., Ono, H. (2001). Characterization of the products resulting from ethylene glycol liquefaction of cellulose. Journal of Wood Science, vol. 47, no. 5, p. 458-464, DOI:10.1007/ BF00767898.
[15]Jasiukaityté, E., Kunaver, M., Strlič, M. (2009). Cellulose liquefaction in acidified ethylene glycol. Cellulose, vol. 16, no. 3, p. 393-405, DOI:10.1007/s10570-009-9288-y.

[16]Jasiukaityté, E. (2010). Identification of Products Obtained by Acid-Catalyzed Cellulose and Lignin Liquefaction with Polyfunctional Alcohols (PhD. thesis). University of Ljubljana, Faculty of Chemistry and Chemical Technology, Ljubljana.

[17]Hassan, E., Shukry, N. (2008). Polyhydric alcohol liquefaction of some lignocellulosic agricultural residues. Industrial Crops and Products, vol. 27, no. 1, p. 33-38, DOI:10.1016/j. indcrop.2007.07.004.

[18]Lefebvre, A.H., Ballal, D.R. (2010). Gas turbine Combustion: Alternative Fuels and Emissions. Taylor \& Francis Group, Boca Raton, DOI:10.1201/9781420086058.

[19]Fengel, D., Wegener, G. (1989). Wood, Chemistry, ultrastructure, Reactions. W. de Gruyter, Berlin, New York.

[20]Warnatz, J., Maas, U., Dibble, R.W. (2006). Combustion: Physical and Chemical Fundamentals, Modeling and Simulation, Experiments, Pollutant Formation, 4th ed. Springer-Verlag, Berlin, Heidelberg.

[21]Hämäläinen, J.P., Aho, M.J. (1995). Effect of fuel composition on the conversion of volatile solid fuel $\mathrm{N}$ to $\mathrm{N}_{2} \mathrm{O}$ and NO. Fuel, vol. 74, no. 12, p. 1922-1924, DOI:10.1016/0016-2361(95)00198-0. 